\title{
ОТЕЧЕСТВЕННЫЙ И ЗАРУБЕЖНЫЙ ОПЫТ В ОБЛАСТИ СОЗДАНИЯ ФОТО- И ТЕРМОХРОМНЫХ МАСКИРУЮЩИХ ПОКРЫТИЙ
}

\author{
Ю.А. Полушковский, И. В. Суровцева, Д.Н. Чигрин, А. П. Маняк, О. К. Струков \\ ЮРИЙ АЛЕКСАНДРОВИЧ ПОЛУШКОВСКИЙ-к.т.н., ведущий научный сотрудник Научно-инжинирин- \\ гового иентра «Перспективные научно-технические проекты» МИРЭА - Российский технологический \\ университет.E-mail: yapolu52@yandex.ru.
}

ИРИНА ВЯЧЕСЛАВОВНА СУРОВЦЕВА - соискатель степени кандидата наук, сотрудник Научно-инжинирингового иентра «Перспективные научно-технические проектыl» МИРЭА - Российский технологический университет. E-mail: surovceva@mirea.ru.

ДМИТРИЙ НИКОЛАЕВИЧ ЧИГРИН - аспирант кафедры радиоэлектронных систем и комплексов, сотрудник Научно-инжинирингового иентра «Перспективные научно-технические проекты»» МИРЭА - Российский технологический университет. E-mail: chigrin@mirea.ru.

АЛЕКСЕЙ ПАВЛОВИЧ МАНЯК - аспирант кафедры оптико-электронных приборов и систем МИРЭА Российский технологический университет. E-mail: manyak@mirea.ru.

ОЛЕГ КОНСТАНТИНОВИЧ СТРУКОВ - аспирант кафедры оптико-электронных приборов и систем МИРЭА - Российский технологический университет. E-mail: strukov@mirea.ru.

119454, Москва, Россия, пр. Вернадского, д.78. МИРЭА - Российский технологический университет (РТУ МИРЭА).

Проанализирован отечественный и зарубежный опыт в области создания фото- и термохромных адаптивных маскирующих покрытий (АМП). Определены мировые разработчики-лидеры АМП и резюмирована динамика патентования тематических исследований. Выявлена тенденция растиренного применения специальных полимеров, сетчатых оптических материалов, работающих в видимом и инфракрасном участках спектрального диапазона. Рассмотрено использование метаматериалов, обладающих специфическими физическими и оптическими свойствами, в части преломления падающего света. Показана реализачия технологии АМП, основанной на применении «клокинг»-эффекта. Общим для отечественных и зарубежных разработчиков являются физико-химические основы технологии создания фото- и термохромных полимерных систем.

Ключевые слова: анализ публикаций, покрытие адаптивное маскирующее, тенденции развития, термохромный материал, фотохромный материал. 


\title{
THE RUSSIAN AND FOREIGN EXPERIENCE IN THE FIELD OF CREATING PHOTO- AND THERMOCHROMIC MASKING COATINGS
}

\author{
Yu.A. Polushkovskij, I. V. Surovceva, D. N. Chigrin, A. P. Maniak, O. K. Strukov \\ MIREA - Russian Technological University (RTU - MIREA), 78 Vernadsky Avenue, Moscow 119454.
}

The Russian and foreign experience in the field of creating photo- and thermochromic adaptive masking coatings (AMC) is analyzed. The global developers-leaders of the AMC are identified and the dynamics of patenting of case studies is summarized. A tendency has been revealed for the expanded use of special polymers, meshys optical materials operating in the visible and infrared spectral ranges. The use of metamaterials with specific physical and optical properties, in terms of refraction of incident light, is considered. An implementation of the AMC technology based on the use of the "clocking" effect is shown. The physical and chemical foundations of the technology for creating photo- and thermochromic polymer systems are common to Russian and foreign developers.

Keywords: analysis of publications, adaptive masking coating, development trends, thermochromic material, photochromic material.

Изученный отечественный и зарубежный опыт в исследуемой области показывает актуальность создания фото- и термохромных маскирующих покрытий для решения прикладных задач.

Разработчики средств маскировки в своей деятельности ранее делали акцент на подбор цветов, рисунка и формы маскирующих покрытий (камуфляжа). При этом неизменность свойств маскирующих покрытий не обеспечивала требуемый уровень незаметности не только с принятием на вооружение оптико-электронных средств наблюдения, но и, что наиболее важно, при динамичной смене фона, а это обусловило появление нового класса маскирующих покрытий - адаптивных. И хотя исследования путей создания таких средств маскировки мировыми разработчиками начались еще в середине прошлого века, наибольшая активность стала проявляться в последние 10-20 лет.

АМП отличается от обычных маскирующих покрытий двумя особенностями. Во-первых, оно подменяет внешний вид объекта маскировки видом совпадающего по ракурсу и перспективе фрагмента фона окружающей среды, то есть максимально точно представляет то, что находится за маскируемым объектом. Во-вторых, АМП функционирует в реальном времени.

Создание адаптивного камуфляжа потребовало применения специальных материалов с заданными отражательными и поглощающими свойствами в различных спектральных диапазонах, а также разработку способов и средств управления рисунком и цветом. Как следствие, особое внима- ние разработчиков новых технологий в области материаловедения уделяется хромогенным материалам, которые представлены в таблице.

Хромогенные материалы позволяют сделать маскируемый объект частично или полностью невидимым, излучающим или поглощающим излучение в том или ином участке спектра при различных условиях окружающей среды, а также при специальных (целевых) воздействиях.

Далее на рисунке представлена динамика патентования, из которой следует, что пик активности патентования термохромных и фотохромных материалов и адаптивных маскирующих покрытий на их основе приходится на 2011-2014 гг., после чего заметен существенный спад.

Такое состояние может свидетельствовать о том, что у мировых разработчиков исчерпаны технологические возможности, а дальнейшие инвестиции в исследования по созданию новых материалов оказались малоэффективными. Это предположение подтверждается тем фактом, что за три года (с 2014 по 2017 гг.) число патентов, выданных на адаптивные маскирующие покрытия, сократилось в 7,7 раза (с 23 до 3 штук). Также наблюдается существенное сокращение открытых публикаций тематических исследований, что подтверждается изучением научно-технических источников.

Существующие маскирующие покрытия можно классифицировать как устройства, отличающиеся по форме (2D и 3D) и по принципу работы: с использованием трансформационной оптики; плазмонные маскирующие устройства; устройства, 
Классификация хромогенных материалов

\begin{tabular}{ll}
\hline \multicolumn{1}{c}{ Класс материала } & \multicolumn{1}{c}{ Факторы воздействия } \\
\hline Фотохромные & Возбуждающим фактором является ультрафиолетовое или инфракрасное излучение. \\
Термохромные & Изменяют цвет при вариациях температуры окружающей среды. \\
Пьезохромные & Материалы показывают изменение в цвете при воздействии механического \\
механохромные) & напряжения. \\
Электрохромные & Изменение оптических свойств после воздействия электрического поля. \\
Хемохромные & Материалы отвечают изменением цвета на химические реакции в окружающей среде, \\
и галохромные & в частности изменения $р$ рН. \\
Сольватохромные & Чувствительны к определенному растворителю (жидкости или газу). \\
\hline
\end{tabular}

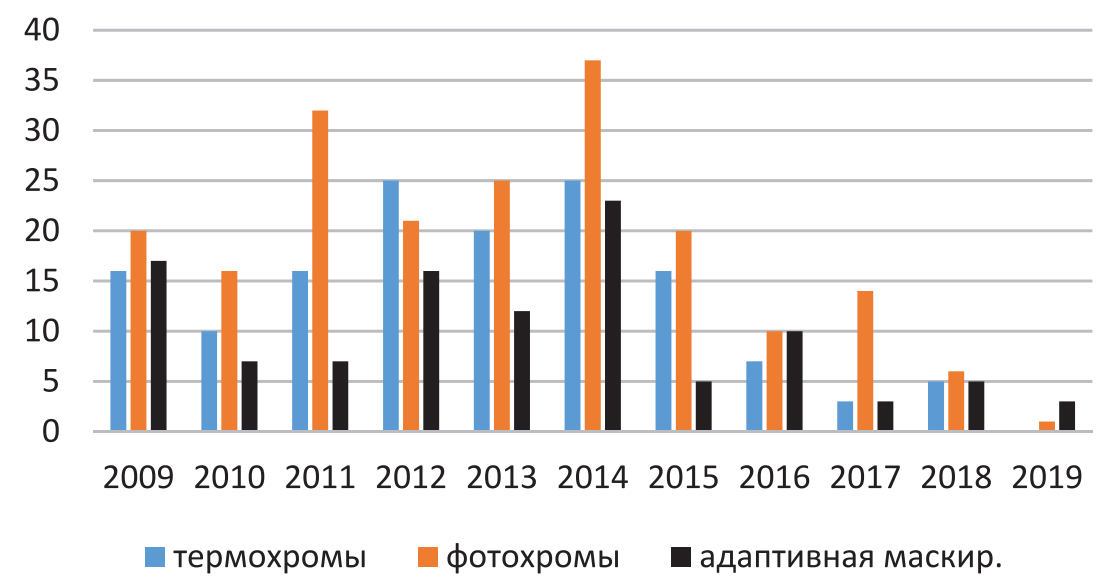
Рис. Динамика патентования термохромных, фотохромных материалов
и адаптивных маскирующих покрытий в 2009-2019 годах

использующие цилиндрический гофрированный рассеиватель [1]; устройства, работающие на аномальном резонансе [2] и т.д. У ведущих мировых разработчиков вызывают интерес метаматериалы, чьи отражательные свойства отличаются от классических, в частности, имеющие отрицательный коэффициент преломления.

В мировой практике наметилась устойчивая тенденция построения АМП с использованием оптико-электронных и проекционных средств, гибких дисплейных матриц и других, отличительной особенностью которых является генерация изображения, реагирующего в ответ на изменения сцен (фона) и условий освещенности.

При всей оригинальности предложенных технических решений АМП объектов, как отечественных, так и зарубежных разработчиков, многие не лишены недостатков, основными из которых являются сравнительная сложность технологии изготовления и ограниченный диапазон усло- вий применения. Например, угловой размер пикселя не должен превышать разрешающую способность глаза (в среднем одну угловую минуту) или устройства обнаружения при пространственном разрешении оптоэлектронного средства не хуже 30 см/пиксель. Тогда при размере $10 \times 10 \mathrm{~cm}$ каждого цветового пятна на маскируемом объекте условие его не распознавания будет выполняться только с дальности 1000 м и более. На меньших дальностях пятна становятся различимыми, что исключает эффект маскировки. Именно решению такого рода инженерных задач уделено особенное внимание отечественных и зарубежных исследователей в области создания АМП.

В результате проанализированных научнотехнических публикаций и патентных источников выявлено более 30 зарубежных фирм, ведущие разработки АМП. Наиболее результативными из них являются: Пенсильванский университет (США); Хьюстонский университет (США); HyperStealth 
Biotechnology Corp. (Канада); Оборонная компания BAE Systems Corp. (Великобритания); Компания Saab Barracuda (Швеция).

Изучение патентных и других открытых источников позволило обобщить результаты, достигнутые зарубежными разработчиками АМП:

1. Реализованы технологии, основанные на новых материалах, что способствует не только изменению их цвета, но также смещению инфракрасного, микроволнового и радиолокационного профилей и слиянию объектов с фоном. В частности, удалось создать класс материалов, позволяющих реализовать эффект обратимости прозрачности и управления цветом на основе гелевых сетей, относящихся к классу хромогенных материалов [3].

2. Разработан и испытан мультиспектральный камуфляж HMBS (High Mobility on-Board System бортовая система для повышенной мобильности), защищающий артиллерийские орудия во время стрельбы и передислокации путем снижения сигнатур до 90 \%. Отмечается, что это АМП также подавляет тепловое излучение двигателей, что позволяет длительно оставлять их работающими на холостом ходу в целях готовности к началу движения.

3. Предложен сверхлегкий многоспектральный камуфляж-экран BMS-ULCAS на основе специального материала, снижающего обнаружение маскируемого объекта в видимом и инфракрасном (ИК) участках спектра. Основной недостаток технологии: каждый экран предназначается специально для маскировки конкретного оборудования.

4. Создан целый ряд метаматериалов:

- с эффектом нарушения оптической взаимности (отражает видимое излучение под разными углами в зависимости от того, с какой стороны приходит падающий луч);

- метаматериал, сформированный из параллельных нанонитей, встроенных внутрь пористого оксида алюминия, отличающийся тем, что его структурная матрица меньше длины волны видимого излучения. Полученный материал с отрицательным показателем преломления отклоняет падающее на него излучение в обратном направлении;

- оптически тонкий наноструктурированный двумерный метаматериал, способный управлять излучением благодаря наноантеннам, размер которых несколько меньше длины волны.

5. В опытных экземплярах АМП реализован эффект трансформационной оптики («клокинг»эффект), основанный на волновом обтекании материальных тел. Технология заключается в изме- нении цвета и узора формы (паттерна) в соответствии с окружающим фоном, что, по мнению разработчиков в перспективе позволит объекту маскировки приобретать невидимость на любой местности и при любых погодных условиях и температуpax. Некоторые длины волн, включая видимый свет, могут быть «изогнуты» в виде потока, обтекающего объект маскировки. В результате, предметы за объектом становятся видимыми, как если бы свет прошел через пустое пространство, в то время сам объект исчезает из виду. Эффективность этого метода подтверждается экспериментально только в случаях малой подвижности объекта. В настоящее время проходят испытания АМП, обладающие значительным недостатком - необходимость подзарядки источников питания, обеспечивающих 8 часов активного функционирования.

6. Определен интеллектуальный подход для создания «умных» АМП на основе текстильных тканей с использованием чувствительных термохромных и фотохромных красителей вместе с обычными пигментами. Принцип работы заключается в трехслойном покрытии: полимерный фотохромный материал, отражающий слой из серебра со специальными светодиодами и внешний термохромный, подогреваемый светодиодами второго слоя. Благодаря такой структуре слоев, камуфляжное полотно при прохождении через него света, изменяет свою окраску. Система на данный момент несовершенна и нуждается в доработке. Но сам принцип оказался весьма действенным. Он открывает широкие перспективы для дальнейшего изучения и развития в сфере маскировки.

7. Показан новый легкий и гибкий термоизоляционный материал, позволяющий полностью скрыть тепловую сигнатуру маскируемого объекта. АМП состоит из трех слоев: верхний из множества подслоев графена служит в качестве электрода, средний слой - мембрана с ионной жидкостью и нижний слой, который также является электродом. Такой «сэндвич» практически мгновенно уменьшает количество инфракрасного излучения поверхностью массируемого объекта. Он также может автоматически приспосабливаться к температуре окружающей среды, позволяя термически смешиваться с окружающей средой.

8. В 2011 году на выставке вооружений DESi2011 представлен танк CV90, снабженный системой Adaptiv, разработанной при участии Агентства по материальному обеспечению вооруженных сил (FMV) Швеции. Этот танк становится невидимым для инфракрасных сенсоров. Более того, система Adaptiv может не только маскировать танк под окружающую местность, но и видоизменять свой тепловой след. Суть разработки заключается в покры- 
тии объекта множеством специальных шестиугольных пластин размером 14 см из термоэлектрического материала, управляемого посредством ЭВМ и ИК камер, регистрирующих ИК изображение фона. При этом полевые испытания показали, что устойчивая «невидимость» работает только на дистанции от 300 до 400 метров. В перспективе планируется охватить другие части спектра. Недостатки: плохая надежность и высокая стоимость.

9. Предложена новая система АМП, представляющая собой сеть гибких плоскопанельных дисплеев, выстроенных в форме «покрывала», которое закрывает все видимые поверхности маскируемого объекта. Каждая дисплейная панель такого АМП содержит активный пиксельный сенсор или, возможно, другой малоразмерный формирователь изображения, который направлен вперед от панели, занимая малую часть площади панели. «Покрывало» содержит проволочный каркас, служащий опорой для сети перекрестно соединенных оптоволоконных нитей, через которые изображение от каждого сенсора передается на дополнительную дисплейную панель на противоположной стороне маскируемого объекта.

Анализ публикаций и патентных источников показал, что основное внимание отечественных разработчиков направлено не только на создание новых материалов, но и на разработку АМП, принцип действия которых основан на «проекции сцены». Большинство отечественных разработок предполагает управление адаптивным маскирующим покрытием, основанное на регистрирующей фон цифровой видеокамере и матрице элементов многослойного покрытия, яркость и цвет которых меняются под управлением ЭВМ. В качестве исполнительного устройства, изменяющего окрашенность, освещенность и другие параметры АМП объекта, предлагается использовать термочувствительные покрытия, меняющие цвет при управляемом нагреве с помощью электрических источников тепла.

У отечественных и у зарубежных разработчиков АМП фотохромные низкомолекулярные соединения (аморфные порошки) в чистом виде практически не находят применения для различных технических приложений в силу их неудовлетворительных эксплуатационных физико-механических свойств. Предпочтение отдается полимерным фотохромным материалам, обладающих рядом преимуществ. В частности, рассматривается применение субстрата в сочетании с фотохромным полимером слоем, который и обеспечивает обратимый переход между неокрашенным и окрашенным состоянием в ответ на управляющее воздействие (нагрев, облучение и др.).
Результаты отечественных исследователей имеют свои отличительные особенности от зарубежных:

1. Отмечаются устройства активного камуфляжа, позволяющие осуществлять адаптацию яркости и цвета покрытия к яркости и цвету фона. Они содержат датчики освещенности маскируемых поверхностей, ориентированные в направлении освещающего пространства и подключенные ко входам устройств управления цветом и яркостью покрытий. Выходы этих устройств подсоединены к многослойным электрически управляемым покрытиям, расположенным на маскируемых поверхностях.

2. В отечественных научных и патентных источниках показано, что низкое энергопотребление системами управления АМП может быть достигнуто с помощью применения светоизлучающего покрытия в виде многослойной матрицы светоизлучающих элементов. Предложен ряд способов реализации адаптивной маскировки объектов [4], объединенных общим принципом: адаптивное управление характеристиками покрытий осуществляется за счет использования многослойных термохромных покрытий, изменяющих цвет и яркость при управляемом нагреве с помощью электрических источников [5].

3. В отечественных разработках АМП по аналогии с зарубежными предлагается использовать многослойные управляемые покрытия, в которых их цвет и яркость изменяются в соответствии с изменением цвета и яркости фона. При этом цвет покрытия формируется путем вариаций соотношения аддитивного сложения пятен трех основных цветов.

4. Предложено маскировочное покрытие, выполненное в виде капиллярных сосудов для циркуляции окрашенной жидкости, управляемой фотокамерой и ЭВМ. Основным недостатком такого устройства является значительная инерционность, которая не позволяет использовать его для маскировки подвижных объектов. Также проявляется неполный диапазон условий маскировки в видимом диапазоне длин волн, так как яркость капилляров с окрашенной жидкостью не в состоянии обеспечить маскировку затененных поверхностей объекта. АМП создает деформирующую визуальную и тепловую окраску. Контраст местности и цели фиксируется многоспектральной фотокамерой и обрабатывается ЭВМ, вырабатываются соответствующие управляющие команды для мини-компрессоров. Программа реализует изменение цвета и температуры поверхности маскируемого объекта в зависимости от давления и температуры воздуха, подаваемого в ячейку. 
5. Предложены термоизолирующие покрытия между объектом и термокрасками, что позволяет не только предохранять объект от внутреннего нагрева, но и обеспечивать необходимый температурный контраст с фоном. Недостаток такого покрытия заключается в том, что снижение контраста в видимом диапазоне длин волн приводит к значительному увеличению контраста в инфракрасном диапазоне.

6. Предлагается АМП с уникальным устройством управления яркостью и цветом фрагментов покрытия. Цвет и яркость покрытия изменяется по сигналам от системы управления не по всему покрытию сразу (как у ряда зарубежных разработок), а в пределах отдельных фрагментов, занимаемых прозрачными коллекторными электродами. Процесс осуществляется последовательно по строкам и столбцам матрицы коллекторных электродов путем их коммутации по сигналам от коммутативного блока, что позволяет сократить до 100 метров минимальную дальность маскировки, т.е. в 10 раз меньше по сравнению с зарубежным прототипом. При этом по полученным изображениям фона в ЭВМ анализируются характеристики фрагментов (пятен) фоновых образований (цвет, яркость и процентное содержание пятен) и выбирается из находящихся в памяти ЭВМ вариантов наиболее соответствующая зарегистрированным характеристикам фона схема деформирующей окраски.

7. В последние годы в связи с активизацией изучения метаматериалов произошел концептуальный и методологический прорыв в разработке АМП объектов [6]. Предложено АМП на основе спиральных резонаторов [7].

Таким образом, анализ отечественного и зарубежного опыта в области создания фото- и термохромных маскирующих покрытий показал:

- отечественные и зарубежные исследователи активно работают над созданием технологии адаптивных маскирующих покрытий, основанных на учете видимого изображения фона, совмещаемого с изображением маскируемого объекта при обязательном применении управляемого маскирующего хромогенного материала. При выборе материалов со специальными свойствами для маскирующего покрытия, кроме цветовых характеристик, учитывается характер изменения коэффициента отражения в зависимости от длины волны;

- наблюдается тенденция расширенного применения специальных полимеров, сетчатых оптических материалов, работающих в видимом и инфракрасном спектральных диапазонах. Веду- щие мировые разработчики АМП сосредоточили свое внимание на создании технологий, основанных на применении «клокинг»-эффекта;

- перспективным является применение метаматериалов, представляющих собой широкий ряд искусственно созданных материалов, которым придаются специфические физические и оптические свойства. Одним из уникальных свойств некоторых видов метаматериалов является то, что они способны эффективно преломить падающий свет таким образом, что объекты, покрытые слоем метаматериала, становятся частично или полностью невидимыми;

- в последние годы возрос интерес к устройствам, разрабатываемым на основе трансформационной оптики, так как они позволяют скрыть объект с любыми материальными параметрами и произвольной формы. И хотя этот физический принцип изначально был разработан для применения в СВЧ-диапазоне, проводимые за рубежом исследования предполагают его использование в видимом и инфракрасном спектральных диапазонах.

\section{Литература}

1. Luukkonen O., Tretyakov S., Alitalo P., Constantin S. Physical Review Letters. 2009. V. 103 (10). P. 103905.

2. McPhedran R.C., Nicorovici N.A., Milton G.W. Physical Review B. 2009. V. 49 (12). P. 8479-8482.

3. Aitken D., Burkinshaw S.M., Griffiths J., Towns A.D. Review of Progress in Coloration and Related Topics. 1996. V. 26 (1). P. 1-8.

4. Устройство адаптивной маскировки объектов: пат. 2313056 Рос. Федерация: МПК F41H 13/01 /Aфанасьева Е.М., Михайлов В.В., Петещенков Э.В.; заявитель и патентообладатель Федеральное государственное казенное военное образовательное учреждение высшего профессионального образования «Военно-воздушная академия имени профессора Н.Е.Жуковского и Ю.А. Гагарина» (г. Воронеж) МО РФ; заявл. 11.05.2013, опубл. 27.09.2015.

5. Устройство адаптивной маскировки объектов: пат. 2552978 Рос. Федерация: МПК F41Н 13/01 /Aфанасьева Е.М., Михайлов В.В., Петещенков Э.В.; заявитель и патентообладатель Федеральное государственное казенное военное образовательное учреждение высшего профессионального образования «Военно-воздушная академия имени профессора Н.Е.Жуковского и Ю.А. Гагарина» (г. Воронеж) МО РФ; заявл. 24.02.2014, опубл. 22.07.2016.

6. Кивмарь Ю.С., Орлов А.А. Научно-технический вестник информационных технологий, механики и оптики. 2012. №3 (79). С. 1-10.

7. Возианова А.В., Ходзиикий М.К. Научно-технический вестник информационных технологий, механики и оптики. 2012. №4 (80). С. 28-33. 